Abstracta Iranicacta Iranica

Revue bibliographique pour le domaine irano-aryen

Volume 34-35-36 | 2017

Comptes rendus des publications de 2011-2013

\title{
Nicholas Sims-Williams. Bactrian Documents from Northern Afghanistan, III: Plates
}

\section{Agnes Korn}

\section{OpenEdition}

1 Journals

\section{Édition électronique}

URL : http://journals.openedition.org/abstractairanica/42021

DOI : 10.4000/abstractairanica.42021

ISSN : 1961-960X

Éditeur :

CNRS (UMR 7528 Mondes iraniens et indiens), Éditions de l'IFRI

Référence électronique

Agnes Korn, "Nicholas Sims-Williams. Bactrian Documents from Northern Afghanistan, III: Plates », Abstracta Iranica [En ligne], Volume 34-35-36 | 2017, document 6, mis en ligne le 30 juillet 2017, consulté le 01 octobre 2020. URL : http://journals.openedition.org/abstractairanica/42021 ; DOI https://doi.org/10.4000/abstractairanica.42021

Ce document a été généré automatiquement le 1 octobre 2020.

Tous droits réservés 


\title{
Nicholas Sims-Williams. Bactrian Documents from Northern Afghanistan, III: Plates
}

\author{
Agnes Korn
}

\section{RÉFÉRENCE}

Nicholas Sims-Williams. Bactrian Documents from Northern Afghanistan, III: Plates. London, Azimuth Editions, 2012, 37 p. +230 planches (Studies in the Khalili Collection, III, Corpus Inscriptionum Iranicarum, Part II, vol. VI: Bactrian)

1 Suivant le plan annoncé dans son premier volume d'édition des manuscrits bactriens (2000), comprenant deux volumes de texte (transcription et traduction anglaise), dont le premier (2000, voir AI-vol.23-Rub.2-1-n.25) présente les « documents légaux et économiques » et le deuxième (2007, voir AI-vol.30-Rub.2-1-n.22) les « lettres et textes bouddhiques ", l'A. a complété en 2012 son édition des manuscrits bactriens avec un volume de planches.

2 L'exécution de l'ensemble de cette œuvre majeure est ainsi achevée avec le volume III des Bactrian Documents from Northern Afghanistan qui présente les photos des manuscrits (dont par ailleurs quelques-uns ont entre-temps disparu) ; ceci est précédé par un catalogue des manuscrits, notant pour chaque manuscrit la collection où il se trouve, la date (pour les manuscrits datés), le format et le nombre de lignes ainsi que les références à ses éditions (y compris des articles référents).

Dans son intention de présenter le corpus des manuscrits bactriens connus de façon la plus complète que possible, l'A. a en même temps repris son premier volume et en a fait une nouvelle édition, incluant les manuscrits à caractère " légal et économique » qui n'étaient pas accessibles au moment de la première édition de ce volume. (Il s'agit des documents $\mathbf{A a}, \mathbf{N n}, \mathbf{S s}, \mathbf{T t}, \mathbf{U u}$ et an, des pièces de bois am no. 30-38 ainsi que le verso 
de $\mathbf{S}$ et le verso et la copie fermée de $\mathbf{0}$.) L'A. offre aussi des lectures révisées (dont quelques-unes sont motivées par un meilleur accès aux originaux).

4 Avec cet ensemble de volumes, l'A. présente un corpus à part entière, enrichissant ainsi une langue iranienne auparavant assez peu connue par des nouvelles ressources, offrant au lecteur un matériel très riche pour des études linguistiques sur le bactrien ainsi que des recherches historiques et économiques de l'Afghanistan ancien.

5 [Ce compte rendu concerne également le $\mathrm{n}^{\circ} 5$ de la rubrique 2-1 de ce même volume]

\section{AUTEURS}

\section{AGNES KORN}

CNRS, Mondes iranien et indien 